\title{
Comparison of Ramosetron Dose in Patients with Postoperative Nausea and Vomiting Who Received Oxycodone-Based Intravenous Patient-Controlled Analgesia after Undergoing Gynecological Laparoscopic Surgery
}

\section{Hyung Youn Gong}

Department of Anesthesiology and Pain Medicine, Soonchunhyang University Choenan Hospital, Choenan, Korea

\begin{abstract}
Objective: Pain that occurs following gynecological laparoscopic surgery is a main cause for prolonged hospitalization. As a solution, various intravenous patient-controlled analgesia (IV PCA) systems have been used to control postoperative pain. This study explored the relationship between the dose of the ramosetron used to control postoperative nausea and vomiting (PONV) and its effect when oxycodone was used as the IV PCA.

Methods: Ninety-two patients (age, 18-70 years) undergoing gynecological laparoscopic surgery received oxycodone as IV PCA and were divided into the RB and RM group. Towards the end of surgery, the RB group patients were given $0.3 \mathrm{mg}$ ramosetron as an IV bolus, and those in the RM group were given $0.3 \mathrm{mg}$ ramosetron plus and additional $0.6 \mathrm{mg}$ as IV PCA. The degree of PONV, postoperative pain, and pain felt during coughing were observed for $0.5,2,4,8,24$, and 48 hours postoperatively. Patient satisfaction and comfort were assessed at 24 and 48 hours.

Results: No differences in operation time, anesthesia period, or amounts of propofol and remifentanil used were observed between the groups. IV PCA demand, severity of PONV, postoperative pain, and coughing pain were also similar between the groups. Patient comfort was similar between the groups at 24 and 48 hours postoperatively.

Conclusion: No difference in the incidence of PONV was detected between patients who used only $0.3 \mathrm{mg}$ ramosetron as an intravenous bolus and those who received an additional $0.6 \mathrm{mg}$ ramosetron mixed in IV PCA when oxycodone was offered as the IV PCA after undergoing gynecological laparoscopic surgery.
\end{abstract}

Keywords: Nausea; Oxycodone; Postoperative nausea and vomiting; Antiemetics; Patient-controlled analgesia

\section{INTRODUCTION}

Intravenous patient-controlled analgesia (IV PCA) is the most effective method for postoperative pain control. However, postoperative nausea and vomiting (PONV) caused by IV PCA opioid use is a very common complication. PONV is related to dehydration, electrolyte balance, recovery delay after surgery, and patient dissatisfaction [1,2]. The etiology of PONV is very complex and is related to patient characteristics, underlying disease, surgery type, anesthesia type, and postoperative management [2]. The overall incidence of PONV is $20 \%-30 \%$ but increases to $80 \%$ in high-risk patients. Patients undergoing gynecological laparoscopic surgery are at high-risk for PONV [2,3].

White et al. [4] reported that total intravenous anesthesia (TIVA) reduces PONV only during the early postoperative period, and that long-term antiemetics are needed. Selective 5-hydroxytryptamine type 3 (5-HT3) antagonists used to prevent PONV are more efficient compared with other antiemetics and produce fewer side effects [5]. Ramosetron (Nasea; Astellas, Tokyo, Japan) is similar to the 5-HT3 receptor antagonist ondansetron and is more effective than granisetron $[6,7]$.

Many studies have been performed on PONV and IV PCA based on fentanyl or morphine, but little research has been performed on PONV in patients with IV PCA using oxycodone. The
Correspondence to: Hyung Youn Gong

Department of anesthesiology, Soonchunhyang University Choenan Hospital, 31 Suncheonhyang 6-gil, Dongnam-gu, Cheonan 31151, Korea

Tel: +82-41-573-2832, Fax: +82-41-573-3559, E-mail: 83466@schmc.ac.kr

Received: Oct. 10, 2018 / Accepted after revision: Oct. 18, 2018
(C) 2018 Soonchunhyang Medical Research Institute

This is an Open Access article distributed under the terms of the Creative Commons Attribution Non-Commercial License (http://creativecommons.org/licenses/by-nc/4.0/). 
Gong HY • Comparison of Ramosetron Dose in Patients Who Received Oxycodone-Based IV PCA

purpose of this study was to explore the relationship between the ramosetron dose used to control PONV when using oxycodone as IV PCA.

\section{MATERIALS AND METHODS}

The American Society of Anesthesiologists physical status 1 or 2 female patients $(n=92$; age, $18-70$ years old) receiving laparoscopic partial hysterectomy participated in this prospective, randomized, and double-blind study. After approval of Soonchunhyang University Choenan Hospital ethics committee (approval no., SCHCA_IRB_2013-70; clinical trial no., KCT0001745), we received patient consent after explaining the purpose and methods of the study to the patients or guardians. Exclusion criteria were pregnancy, obesity, history of PONV, bleeding tendency, mental disorder, hepatitis or renal failure, and recent history of taking steroids or antiemetics.

Glycopyrrolate $(0.2 \mathrm{mg})$ was injected intramuscularly $30 \mathrm{~min}-$ utes before surgery as premedication. Basic monitoring, such as electrocardiogram, noninvasive blood pressure, and pulse oximetry were started after the patient arrived in the operating room. Propofol (target effect site concentration, $2.5-4 \mu \mathrm{g} / \mathrm{mL}$ ), remifentanil (Ultiva; GSK, Rome, Italy; target effect site concentration, 2-4 $\mathrm{ng} / \mathrm{mL}$ ), and $0.6 \mathrm{mg} / \mathrm{kg}$ rocuronium bromide (Esmeron; Organon, Best, the Netherlands) were injected to induce general anesthesia before tracheal intubation. We mechanically ventilated the subjects with mixed $\mathrm{O}_{2} /$ air $\left(\mathrm{FiO}_{2}, 0.4\right)$ gas and maintained $\mathrm{ETCO}_{2}$ at 35-40 mm Hg. Glycopyrrolate and pyridostigmine was administered to all patients to reverse anesthesia. Residual muscle relaxation was detected before the operation was finished.

Oxycodone (5 $\mathrm{mg})$ and ramosetron $(0.3 \mathrm{mg})$ were injected to regulate pain 5 minutes after the end of the operation. IV PCA was divided randomly into the $\mathrm{RB}$ and $\mathrm{RM}$ groups. The group $\mathrm{RB}$ received $10 \mathrm{~mL}$ of a mixed solution made with $1 \mathrm{mg} / \mathrm{kg}$ oxycodone, $150 \mathrm{mg}$ ketorolac, and physiological saline. The RM group received the same but $0.6 \mathrm{mg}$ ramosetron was added. IV PCA was programmed to deliver $2 \mathrm{~mL} / \mathrm{hr}$ as the background infusion and $0.5 \mathrm{~mL}$ per demand with a 15 minutes lockout during the 48 hours postoperative period.

PONV and pain were evaluated $0.5,2,4,8,24$, and 48 hours after transfer to the recovery room by a researcher who was not involved in the anesthesia. Patient satisfaction was evaluated at 24 and 48 hours. Four patients in the RM group were excluded be- cause they stopped the IV PCA prior to 24 hours. A numeric rating scale was used to evaluate the degree of PONV, pain, and patient satisfaction using 5 grades of very good, good, normal, bad, and very bad.

Statistical analyses were performed with PASW SPSS ver. 18.0 software (SPSS Inc., Chicago, IL, USA). Categorical data are presented as mean \pm standard deviation. Repeated-measures analysis of variance was performed to compare the groups, and a P-value $<0.05$ was considered significant. Sample size was obtained using G-power ver. 3.1.7 (Heinrich-Heine-Universität Düsseldorf, Düsseldorf, Germany; http://www.gpower.hhu.de/) with $\alpha=0.05$, power $(1-\beta)=0.8$, and effect size $=0.25$.

\section{RESULTS}

No differences in patient age, weight, height, operation time, anesthesia time, or propofol and remifentanil volumes were detected between the two groups (Table 1). No difference in PCA usage was observed between the two groups $(\mathrm{P}>0.05, \mathrm{P}=0.077)$ (Fig. 1). No differences in the degree of nausea and vomiting were detected at any sampling time between the groups $(\mathrm{P}>0.05$, $\mathrm{P}=0.578$ ) (Fig. 2). No differences in the degree of resting pain or coughing pain were detected between the groups at $0.5,2,4$, or 8 hours $(\mathrm{P}>0.05)$ but the differences were significant between the groups at 24 and 48 hours $(\mathrm{P}<0.05)$ (Figs. 3, 4). No differences in patient satisfaction at 24 or 48 hours were detected between the groups $(\mathrm{P}>0.05 ; 24$ hours, $\mathrm{P}=0.830 ; 48$ hours, $\mathrm{P}=0.611)$ (Table 2$)$.

\section{DISCUSSION}

We studied the degree of pain and PONV in patients who used

Table 1. Demographic data and operative data

\begin{tabular}{lccc}
\hline Characteristic & $\begin{array}{c}\text { Group RB } \\
(\mathrm{n}=46)\end{array}$ & $\begin{array}{c}\text { Group RM } \\
(\mathrm{n}=42)\end{array}$ & P-value \\
\hline Age (yr) & $45.98 \pm 5.49$ & $47.52 \pm 6.53$ & 0.231 \\
Weight $(\mathrm{kg})$ & $60.34 \pm 8.57$ & $64.40 \pm 11.11$ & 0.057 \\
Height $(\mathrm{cm})$ & $159.23 \pm 4.38$ & $158.45 \pm 4.97$ & 0.435 \\
Operation time (min) & $73.7 \pm 38.62$ & $70.71 \pm 27.15$ & 0.679 \\
Anesthesia time (min) & $98.70 \pm 38.02$ & $92.62 \pm 24.02$ & 0.378 \\
Propofol (mg) & $994.28 \pm 390.60$ & $900.38 \pm 298.94$ & 0.212 \\
Remifentanil (mcg) & $932.20 \pm 379.09$ & $726.50 \pm 271.83$ & 0.140 \\
\hline
\end{tabular}

Values are presented as mean \pm standard deviation.

a)Ramosetron $0.3 \mathrm{mg}$ intravenous bolus. ${ }^{b}$ Ramosetron $0.3 \mathrm{mg}$ intravenous bolus plus $0.6 \mathrm{mg}$ mixed in patient-controlled analgesia. 


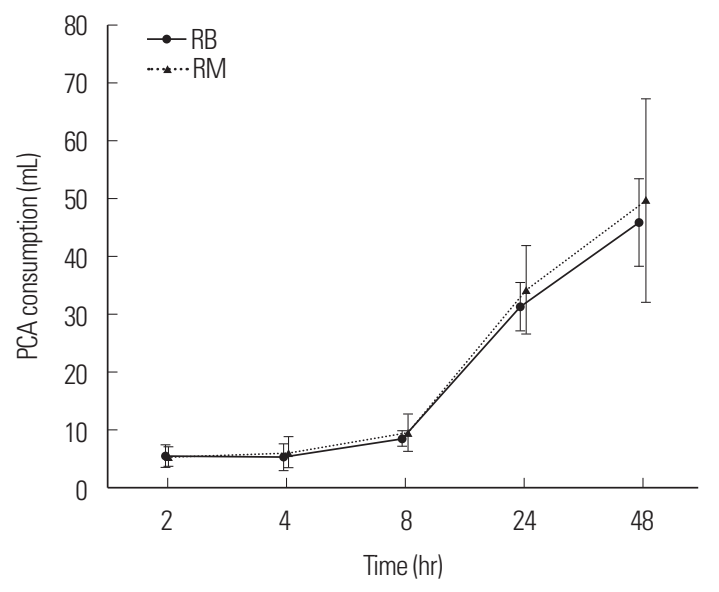

Fig. 1. Change of PCA consumption with time after postanesthetic care unit administration. Group RB: ramosetron 0.3 mg intravenous bolus, Group RM: ramosetron $0.3 \mathrm{mg}$ intravenous bolus plus $0.6 \mathrm{mg}$ mixed in PCA. PCA, patient-controlled analgesia.

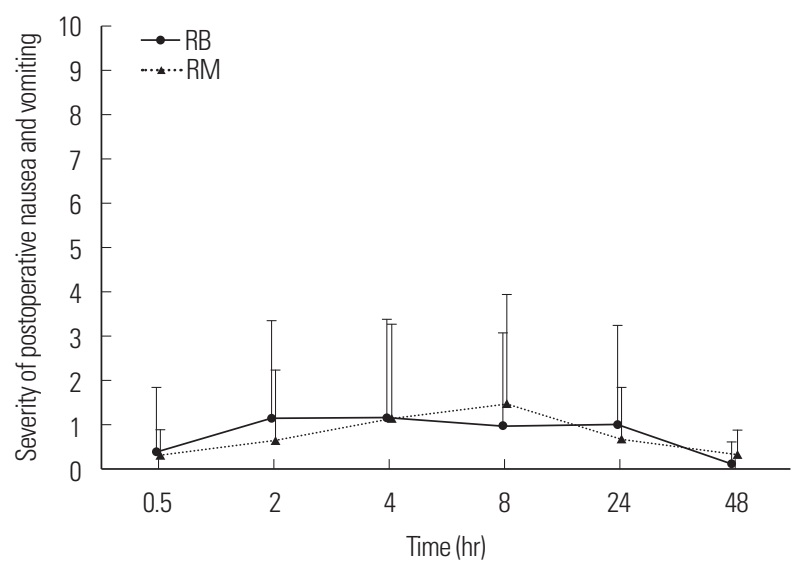

Fig. 2. The severity of postoperative nausea and vomiting with time after postanesthetic care unit administration. Group RB: ramosetron $0.3 \mathrm{mg}$ intravenous bolus, Group RM: ramosetron $0.3 \mathrm{mg}$ intravenous bolus plus $0.6 \mathrm{mg}$ mixed in patient-controlled analgesia.

Table 2. Satisfaction scores at 24 and 48 hours after surgery

\begin{tabular}{lccc}
\hline & $\begin{array}{c}\text { Group } \mathrm{RB}^{\text {a) }} \\
(\mathrm{n}=46)\end{array}$ & $\begin{array}{c}\text { Group } \mathrm{RM}^{\text {b) }} \\
(\mathrm{n}=42)\end{array}$ & P-value \\
\hline $24 \mathrm{hr}$ & $3.89 \pm 0.52$ & $3.92 \pm 0.64$ & 0.830 \\
$48 \mathrm{hr}$ & $3.93 \pm 0.61$ & $3.86 \pm 0.63$ & 0.611 \\
\hline
\end{tabular}

Values are presented as mean \pm standard deviation.

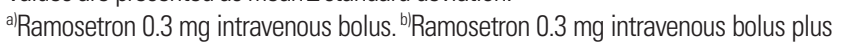
$0.6 \mathrm{mg}$ mixed in patient-controlled analgesia.

IV PVA with oxycodone and various amounts of ramosetron in a prospective, randomized, and double-blind study.

The causes of PONV vary based on sex, age, obesity, history of PONV, smoking, anesthesia, and opioid use. Moreover, abdomi-

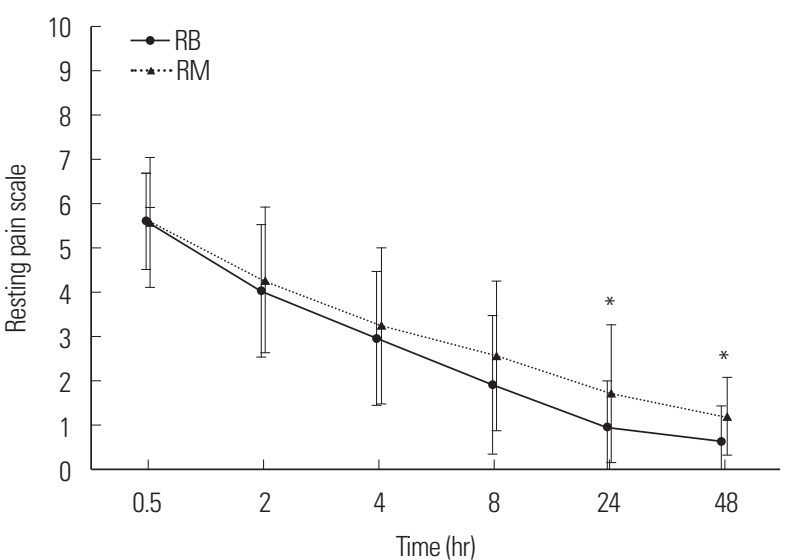

Fig. 3. The resting pain scale with time after postanesthetic care unit administration. Group RB: ramosetron 0.3 mg intravenous bolus, Group RM: ramosetron $0.3 \mathrm{mg}$ intravenous bolus plus $0.6 \mathrm{mg}$ mixed in patient-controlled analgesia. ${ }^{*} \mathrm{P}<0.05$ between both group.

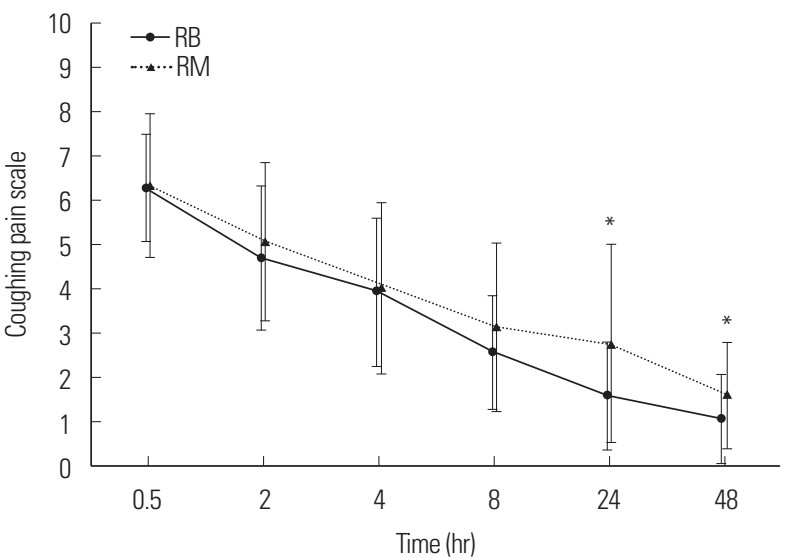

Fig. 4. The coughing pain scale with time after postanesthetic care unit administration. Group RB: ramosetron $0.3 \mathrm{mg}$ intravenous bolus, Group RM: ramosetron $0.3 \mathrm{mg}$ intravenous bolus plus $0.6 \mathrm{mg}$ mixed in patient-controlled analgesia. ${ }^{*} \mathrm{P}<0.05$ between both group.

nal distension, peritoneal irritation, irritation of the diaphragm and intestine, and a pneumoperitoneum caused by $\mathrm{CO}_{2}$ remaining after laparoscopy affect the incidence of PONV [8,9]. All patients in this study were women who use opiates for pain control, were non-smokers, and underwent gynecological surgery. Thus, most patients had three or more risk factors.

Opioid-based IV PCA is effective and patients are highly satisfied the postoperative pain control. However, PONV increases approximately $30 \%$ in patients who control their postoperative pain with an opioid [10,11]. Moreover, PONV may delay surgical recovery, cause dehydration and abnormal electrolytes, and increase hospital stay. Thus, appropriate pain control is helpful in terms of 
Gong HY • Comparison of Ramosetron Dose in Patients Who Received Oxycodone-Based IV PCA

reducing hospital stay and costs. Therefore, it is necessary to evaluate preventing PONV using opioid-based IV PCA [2,4,12].

Oxycodone is a thebaine derivative that is pharmacologically similar to morphine and effective for both somatic and visceral pain [13] and is used to treat acute and chronic pain [14]. The introduction of injectable oxycodone has allowed it use in IV PCA. The analgesic effects of oxycodone are similar to or better than those of fentanyl, and the analgesic affect is longer [14,15]. Oxycodone has side effects similar to other opioids but produces less nausea and itching compared with those of morphine [15].

In this study, the initial amount of ramosetron injected was set to $0.3 \mathrm{mg}$ for both groups based on another study that compared results after $0.15,0.3$, and $0.6 \mathrm{mg}$ ramosetron injections and found that $0.3 \mathrm{mg}$ was not different from $0.6 \mathrm{mg}$ regarding the PONV effect but was better than the 0.15 injected group [16].

The early postoperative increase in PONV in our study may have been related to the short-term influence of propofol as White et al. [4] mentioned. Hence, even if TIVA was used, a longer acting anti-emetic is needed to reduce PONV. A systematic review of 84 randomized controlled studies found that the group using propofol had more PONV during the early 6 hours postoperative period compared with the group that used a volatile agent [17]. Ramosetron has a longer and more powerful effect than 5-HT3 receptor antagonists. The half-life of propofol is about 9 hours, which is longer than ondansetron and granisetron (3.5 and 4.9 hours, respectively) [18-20]. Apfel et al. [21] reported a difference in risk factors for early PONV (0-2 hours) and late PONV (2-24 hours). According to Lee et al. [22], $0.3 \mathrm{mg}$ ramosetron effectively prevents PONV for 1 hour after gynecological laparoscope surgical procedures. We found that the incidence of PONV did not increase up to 6 hours postoperatively, regardless of the sustained injection. We compared two groups based on the research of Fujii and Tanaka [16] who used 0.3 and $0.9 \mathrm{mg}$ each; however, no difference in the PONV effect was observed. Therefore, use the full $0.3 \mathrm{mg}$ for 48 hours postoperatively is more economical than using $0.9 \mathrm{mg}$, which resulted in a significant difference in the resting and coughing pain scores at 24 and 48 hours. However, the actual score was within a 1 point of difference, which is not clinically significant. Therefore, administering additional ramosetron intravenously 2 hours after surgery is expected to prevent of PONV rather than continued injections after surgery method, but additional studies are needed to verify this hypothesis.

A limitation of this study was the difference in operative time and surgical technique by the surgeon. Second, specific ages of patients are susceptible to PONV. Third, we had no PONV reference point with a placebo. However, using a placebo in patients at highrisk for PONV is an ethical problem.

In conclusion, no difference in the effect of using a $0.3 \mathrm{mg}$ ramosetron intravenous bolus and adding $0.6 \mathrm{mg}$ ramosetron mixed in IV PCA was observed when oxycodone was offered as IV PCA after gynecological laparoscopic surgery.

\section{REFERENCES}

1. Jellish WS, Leonetti JP, Sawicki K, Anderson D, Origitano TC. Morphine/ ondansetron PCA for postoperative pain, nausea, and vomiting after skull base surgery. Otolaryngol Head Neck Surg 2006;135:175-81.

2. Watcha MF, White PF. Postoperative nausea and vomiting: its etiology, treatment, and prevention. Anesthesiology 1992;77:162-84.

3. Apfel CC, Laara E, Koivuranta M, Greim CA, Roewer N. A simplified risk score for predicting postoperative nausea and vomiting: conclusions from cross-validations between two centers. Anesthesiology 1999;91:693700.

4. White H, Black RJ, Jones M, Mar Fan GC. Randomized comparison of two anti-emetic strategies in high-risk patients undergoing day-case gynaecological surgery. Br J Anaesth 2007;98:470-6.

5. Habib AS, Gan TJ. Evidence-based management of postoperative nausea and vomiting: a review. Can J Anaesth 2004;51:326-41.

6. Fujii Y, Saitoh Y, Tanaka H, Toyooka H. Comparison of ramosetron and granisetron for preventing postoperative nausea and vomiting after gynecologic surgery. Anesth Analg 1999;89:476-9.

7. Kim SI, Kim SC, Baek YH, Ok SY, Kim SH. Comparison of ramosetron with ondansetron for prevention of postoperative nausea and vomiting in patients undergoing gynaecological surgery. Br J Anaesth 2009;103: 549-53.

8. Feo CV, Sortini D, Ragazzi R, De Palma M, Liboni A. Randomized clinical trial of the effect of preoperative dexamethasone on nausea and vomiting after laparoscopic cholecystectomy. Br J Surg 2006;93:295-9.

9. Nesek-Adam V, Grizelj-Stojcic E, Rasic Z, Cala Z, Mrsic V, Smiljanic A. Comparison of dexamethasone, metoclopramide, and their combination in the prevention of postoperative nausea and vomiting after laparoscopic cholecystectomy. Surg Endosc 2007;21:607-12.

10. Gepstein R, Arinzon Z, Folman Y, Shuval I, Shabat S. Efficacy and complications of patient-controlled analgesia treatment after spinal surgery. Surg Neurol 2007;67:360-6.

11. Okamura K, Sanuki M, Kinoshita H, Fujii K, Matsunaga A. Study of nausea and vomiting accompanying intravenous patient-controlled analgesia with fentanyl after cervical spine surgery. Masui 2003;52:1181-5.

12. Fujii $\mathrm{Y}$, Tanaka H, Toyooka H. Optimal anti-emetic dose of granisetron for preventing postoperative nausea and vomiting. Can J Anaesth 1994; 41:794-7.

13. Lenz H, Sandvik L, Qvigstad E, Bjerkelund CE, Raeder J. A comparison of intravenous oxycodone and intravenous morphine in patient-controlled postoperative analgesia after laparoscopic hysterectomy. Anesth Analg 2009;109:1279-83.

14. Ordonez Gallego A, Gonzalez Baron M, Espinosa Arranz E. Oxycodone: a pharmacological and clinical review. Clin Transl Oncol 2007;9:298-307.

15. Koch S, Ahlburg P, Spangsberg N, Brock B, Tonnesen E, Nikolajsen L. 
Oxycodone vs. fentanyl in the treatment of early post-operative pain after laparoscopic cholecystectomy: a randomised double-blind study. Acta Anaesthesiol Scand 2008;52:845-50.

16. Fujii Y, Tanaka H. Double-blind, placebo-controlled, dose-ranging study of ramosetron for the prevention of nausea and vomiting after thyroidectomy. Clin Ther 2002;24:1148-53.

17. Tramer M, Moore A, McQuay H. Propofol anaesthesia and postoperative nausea and vomiting: quantitative systematic review of randomized controlled studies. Br J Anaesth 1997;78:247-55.

18. Kang YK, Park YH, Ryoo BY, Bang YJ, Cho KS, Shin DB, et al. Ramosetron for the prevention of cisplatin-induced acute emesis: a prospective randomized comparison with granisetron. J Int Med Res 2002;30:220-9.
19. Rabasseda X. Ramosetron, a 5-HT3 receptor antagonist for the control of nausea and vomiting. Drugs Today (Barc) 2002;38:75-89.

20. Gan TJ. Selective serotonin 5-HT3 receptor antagonists for postoperative nausea and vomiting: are they all the same? CNS Drugs 2005;19:225-38.

21. Apfel CC, Kranke P, Katz MH, Goepfert C, Papenfuss T, Rauch S, et al. Volatile anaesthetics may be the main cause of early but not delayed postoperative vomiting: a randomized controlled trial of factorial design. Br J Anaesth 2002;88:659-68.

22. Lee D, Kim JY, Shin JW, Ku CH, Park YS, Kwak HJ. The effect of oral and IV ramosetron on postoperative nausea and vomiting in patients undergoing gynecological laparoscopy with total intravenous anesthesia. J Anesth 2009;23:46-50. 